This item was submitted to Loughborough's Research Repository by the author.

Items in Figshare are protected by copyright, with all rights reserved, unless otherwise indicated.

\title{
The role of functional variability in a whole body co-ordinated movement - application to high bar giant circles
}

PLEASE CITE THE PUBLISHED VERSION

http://dx.doi.org/10.1016/j.humov.2016.06.011

PUBLISHER

(c) Elsevier

VERSION

AM (Accepted Manuscript)

\section{PUBLISHER STATEMENT}

This work is made available according to the conditions of the Creative Commons Attribution-NonCommercialNoDerivatives 4.0 International (CC BY-NC-ND 4.0) licence. Full details of this licence are available at: https://creativecommons.org/licenses/by-nc-nd/4.0/

\section{LICENCE}

CC BY-NC-ND 4.0

\section{REPOSITORY RECORD}

Hiley, Michael, and Fred Yeadon. 2016. "The Role of Functional Variability in a Whole Body Co-ordinated Movement - Application to High Bar Giant Circles”. Loughborough University. https://hdl.handle.net/2134/22075. 
Human Movement Science 49, 95-103

\title{
The role of functional variability in a whole body co-ordinated movement: application to high bar giant circles
}

\author{
Michael J. Hiley ${ }^{1}$ and Maurice R. Yeadon ${ }^{1}$ \\ ${ }^{1}$ School of Sport, Exercise \& Health Sciences, Loughborough University, Loughborough, UK
}

\begin{abstract}
When performing a giant circle on high bar a gymnast flexes at the hips in the lower part of the circle, increasing the kinetic energy, and extends in the upper part of the circle, decreasing the kinetic energy. In order to perform a sequence of giant circles at even tempo, any variation in angular velocity at the end of the flexion phase needs to be reduced by the end of the extension phase. The aim of this study was to determine the nature and contribution of such adjustments. A computer simulation model of a gymnast performing giant circles on high bar was used to investigate strategies of (a) fixed timing of the extension phase (feedforward control) and (b) stretched timing in order to extend at the same point of the giant circle (feedforward with additional feedback control). For three elite gymnasts fixed timing reduced the angular velocity variation on average by $36 \%$ whereas stretched timing reduced the variation by $63 \%$. The mean reduction for the actual gymnast techniques was $61 \%$. It was concluded that both feedforward and feedback control strategies are used by gymnasts for controlling such movements.
\end{abstract}

\section{INTRODUCTION}

In discrete rapid movements an athlete may select an overall duration for performing the task (Shapiro, 1977) which is then carried out in a feedforward (open loop) manner. In such cases the relative timing of events within the movement has been shown to be invariant, in that all components of the movement are scaled in time (Shapiro, 1977). In ongoing tasks, that are longer in duration, pace may be regulated using feedback (closed loop) control (Jagacinski \& Flach, 2003).

When a gymnast performs regular giant circles on the high bar (Figure 1) the aim is to swing with as little deviation in body form as possible (i.e. minimal use of the hip and shoulder). Regular giant circles are used to link skills performed within a high bar routine. If the circles are used to increase the gymnast's average angular velocity about the bar, in preparation for a release or dismount skill, they are referred to as accelerated giant circles (Cheetham et al., 1984). The gymnast and bar are a mechanical system, where the gymnast can use muscular actions at the hip and shoulder to input or dissipate energy (Bauer, 1983; Yeadon \& Hiley, 2000). As the gymnast passes beneath the bar, the hip and shoulder angles are closed (hip flexion and shoulder extension) which increases both the potential and kinetic energy in the system (Bauer, 1983; Sevrez et al., 2009). As the gymnast passes through the upper part of the circle, opening the hip and shoulder angles increases the potential energy but decreases the kinetic energy. By varying the timing and amount of extension (opening the hip and shoulder angles) the gymnast can control the energy within the system and thus regulate the speed of rotation.

Hiley et al. (2013) showed that in consecutive regular giant circles, where the gymnasts had been instructed to perform the circles with good form and even tempo, the mechanically important actions (called the "tap", Figure 1 (1) to (2) in the lower part of the circle were performed with low spatial and temporal variability. However, in the actions performed as the gymnasts passed through the upper part of the circle (Figure 1 (2) to (4), the movement variability was found to be significantly higher. It was speculated that the higher variability was due to the gymnasts making feedback corrections in order to keep the giant circles on time (Hiley et al., 2013). Sevrez et al. 
(2009) attached weights to gymnasts' legs to increase the moment of inertia about the bar during regular giant circles. When looking at the actions performed beneath the bar it was reported that with changing duration of the circle, due to increased moment of inertia, the gymnasts' actions were invariant in terms of the position within the circle rather than being temporally invariant. No data were reported on the gymnasts' extension through the upper part of the circle.

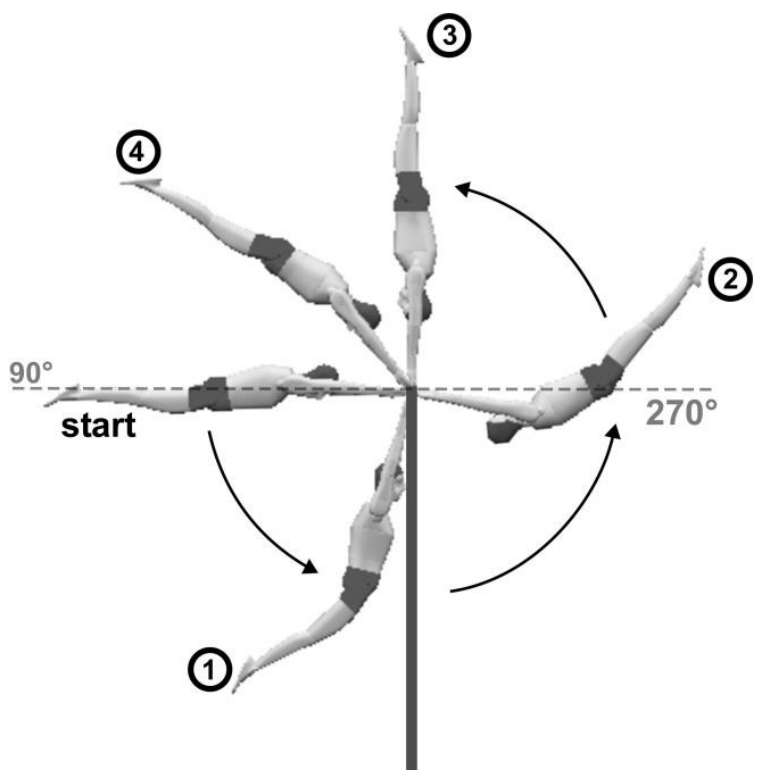

Figure 1. Giant circle showing points of greatest opening (1) and (3) and closing (2) and (4) of the hip and shoulder.

Movement variability is often reported to have a functional role, which is referred to as the flexibility or adaptability of the system to external variability (Preatoni et al., 2013; Hamill et al., 1999; Bartlett et al., 2007). An increase in movement variability associated with a gymnast making feedback corrections would fall under the definition of functional variability since the adjustments have the function of controlling the pace of the giant circle. Feedback control has been demonstrated in a number of gymnastics activities such as hand balance (Yeadon \& Trewartha, 2003) and twisting somersaults (Yeadon \& Mikulcik, 1996; Yeadon \& Hiley, 2014). In both cases the control strategy was based on detecting an error in the desired state and providing a correction, based on the mechanics of the system, after an appropriate time delay (Latash, 1998; Jagacinski \& Flach, 2003). When looking at repeated trials of the same skill it may therefore appear as though there is increased movement variability in certain aspects due to feedback control. However, in order to maintain low variability in the outcome of the movement each feedback correction must still be performed with accuracy (Yeadon \& Hiley, 2014).

The aim of the present study is to determine the nature and contribution of technique and adjustments to the control of pace during consecutive regular giant circles. This comprises the contributions of feedback control, feedforward control and any passive control inherent in the gymnast - bar system.

\section{METHODS}

The variability within consecutive giant circles performed by elite gymnasts was determined and was compared with the variability of simulated strategies.

\section{Data Collection}

Three elite male gymnasts (age $21 \pm 3$ years, mass $69.8 \pm 1.6 \mathrm{~kg}$, height $1.72 \pm 0.03$ $\mathrm{m}$ ) who competed internationally gave informed consent to participate in the study 
which was approved by the university's ethics committee. The gymnasts performed 10 consecutive regular giant circles, performed with even tempo and good form. All trials were captured using 15 Vicon MX13 cameras operating at $300 \mathrm{~Hz}$. Spherical reflective markers, $25 \mathrm{~mm}$ in diameter, were attached to the lateral side of the wrist, elbow, shoulder, hip, knee and ankle joint centres and toes on the left side of the body. Offset measurements from each marker centre to the adjacent joint centre were recorded for subsequent location of the joint centres. Additional markers were attached to the front and rear of the gymnast's head and to the centre of the high bar. Prior to data collection a volume centred on the high bar spanning $2 \mathrm{~m} \times 5 \mathrm{~m} \times 5 \mathrm{~m}$ was wand calibrated using the motion analysis system.

\section{Data Processing}

Three-dimensional marker coordinates were reconstructed and joint centres calculated using the measured offsets. Interpolating quintic splines were fitted to the reconstructed coordinate data to up-sample the data series at $1000 \mathrm{~Hz}$. Joint angles were calculated from the joint centre coordinates. The whole body centre of mass location was determined using subject-specific inertia data (Yeadon, 1990). The rotation angle was defined as the angle made by the line joining the gymnast's centre of mass to the bar location with the upward vertical.

For each giant circle the whole body angular velocity at key rotation angles were noted: start of the giant circle with the body horizontal $\left(90^{\circ}\right)$, at the lowest point of the giant circle $\left(180^{\circ}\right)$, after completing the closing of the hip and shoulder angles $\left(\sim 290^{\circ}\right)$, at the highest point of the circle $\left(360^{\circ}\right)$, and the end of the giant circle $\left(450^{\circ}\right)$. The mean and standard deviation of the angular velocity at each instant were calculated (Table 1). The actions beneath the bar resulted in variability in the whole body angular velocity at the start $\left(\sim 290^{\circ}\right)$ of the upper part of the circle. By the time the gymnast had reached the end of the circle $\left(450^{\circ}\right)$ the variability had been reduced (Table 1$)$.

Table 1. Angular velocities (mean \pm standard deviation) at five points of a giant circle for three gymnasts

\begin{tabular}{cccccc}
\hline & \multicolumn{5}{c}{ Whole body angular velocity $\left[{ }^{\circ} / \mathrm{s}\right]$ at } \\
Gymnast & $\begin{array}{c}\text { start } \\
{\left[90^{\circ}\right]}\end{array}$ & $\begin{array}{c}\text { lowest point } \\
{\left[180^{\circ}\right]}\end{array}$ & $\begin{array}{c}\text { end of tap* } \\
{\left[290^{\circ}\right]}\end{array}$ & $\begin{array}{c}\text { highest point } \\
{\left[360^{\circ}\right]}\end{array}$ & $\begin{array}{c}\text { end } \\
{\left[450^{\circ}\right]}\end{array}$ \\
\hline 1 & $209.9 \pm 2.2$ & $273.1 \pm 1.6$ & $212.8 \pm 7.4$ & $91.4 \pm 13.1$ & $209.6 \pm 2.3$ \\
2 & $219.7 \pm 2.1$ & $281.7 \pm 1.7$ & $217.2 \pm 3.1$ & $78.0 \pm 5.7$ & $220.5 \pm 1.4$ \\
3 & $209.4 \pm 2.2$ & $277.1 \pm 1.7$ & $215.1 \pm 5.2$ & $84.2 \pm 6.9$ & $209.6 \pm 2.2$ \\
\hline
\end{tabular}

Note: * end of tap refers to the rotation angle once the closing of the shoulder angle was complete

The variability analysis described by Hiley et al. (2013) was carried out to confirm that the three gymnasts followed the trend of low movement variability through the lower part of the circle and high variability through the upper part. The events of maximum and minimum hip and shoulder flexion and extension were identified from the respective joint angle time histories and times and angles were noted. Time zero corresponded to a rotation angle of $90^{\circ}$ (Figure 1 "start"). The giant circles were completed once the gymnast had rotated through a full $360^{\circ}$ to a rotation angle of $450^{\circ}$. The mean and 
standard deviation (SD) were calculated for angles and times at each extremum over the 10 trials.

\section{Simulation model}

To determine the strategy used to control the pace of regular giant circles a planar four-segment angle-driven model of a gymnast (comprising arm, torso, thigh and lower leg segments) and bar was used (Hiley \& Yeadon, 2003a). The bar and the gymnast's shoulder structure were modelled as damped linear springs (Figure 2). The spring at the shoulder represented the increase in length of the gymnast between the wrist and the hip. In addition to the shoulder spring, the torso segment was allowed to lengthen as the shoulder elevation angle increased (Begon, Weiber \& Yeadon, 2008).

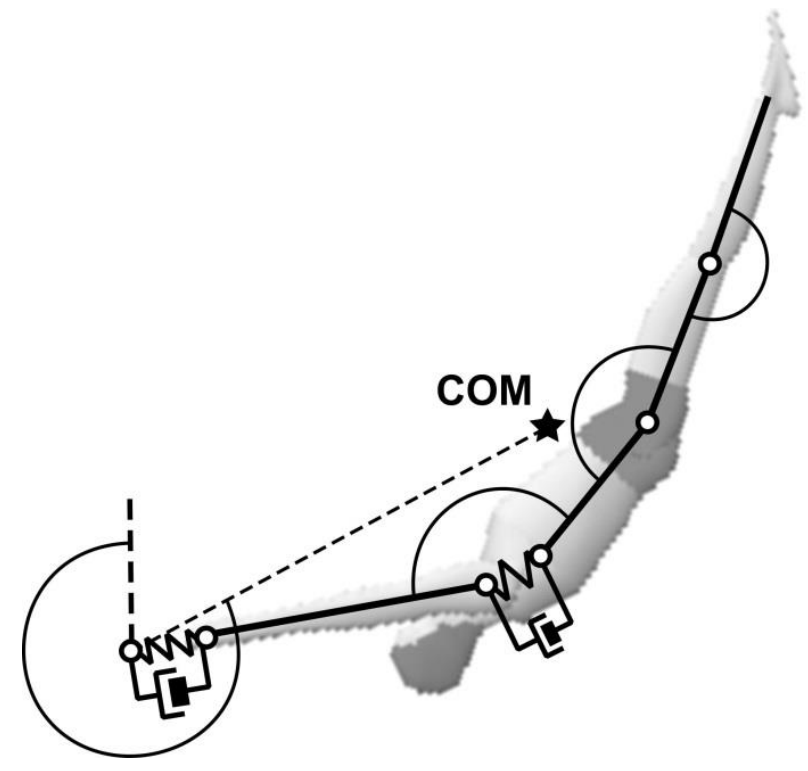

Figure 2. Simulation model of the gymnast and high bar with the rotation angle and joint angle definitions.

Model parameters comprised segmental inertia data calculated from anthropometric measurements and Yeadon's (1990) geometric inertia model, stiffness and damping coefficients of the bar and shoulder springs, and the torso lengthening parameter were calculated using a matching simulation. The initial conditions comprised the initial displacement and velocity of the bar, initial angular velocity of the arm, and initial orientation of the arm. Input to the model comprised the joint angle time histories of the shoulder, hip and knee in the form of quintic splines (Wood \& Jennings, 1979). Output from the model included the time histories of the horizontal and vertical bar displacements, the rotation angle (the angle between the upward vertical and the line from the neutral bar position to the model mass centre), and the energy of the system. The equations of motion were derived using Newton's Second Law and by taking moments about the neutral (unloaded) bar position and the segment mass centres (Hiley \& Yeadon, 2003a).

\section{Matching Simulations}

For each gymnast an average matching simulation was obtained where the model was driven using the average joint angle time histories obtained from the 10 trials (Figure 3). The matching score was based on minimising the root mean squared difference between the recorded and simulated rotation angle and bar displacements (Hiley \& Yeadon, 2003b). The matching procedure was used to produce a common set of bar parameters for all gymnasts (i.e. bar stiffness and damping coefficients). Each 
simulation was started from the rotation angle at the end of the tap ( $290^{\circ}$, Table 1$)$ and finished at a rotation angle of $450^{\circ}$. The matching simulations $(n=3)$ were on average able to match the rotation angle to $0.5^{\circ}$ and the bar displacements to $0.003 \mathrm{~m}$ (Figure 4). The stiffness and damping coefficients of the bar were $21506 \mathrm{~N} / \mathrm{m}$ and $170 \mathrm{Ns} / \mathrm{m}$, respectively.

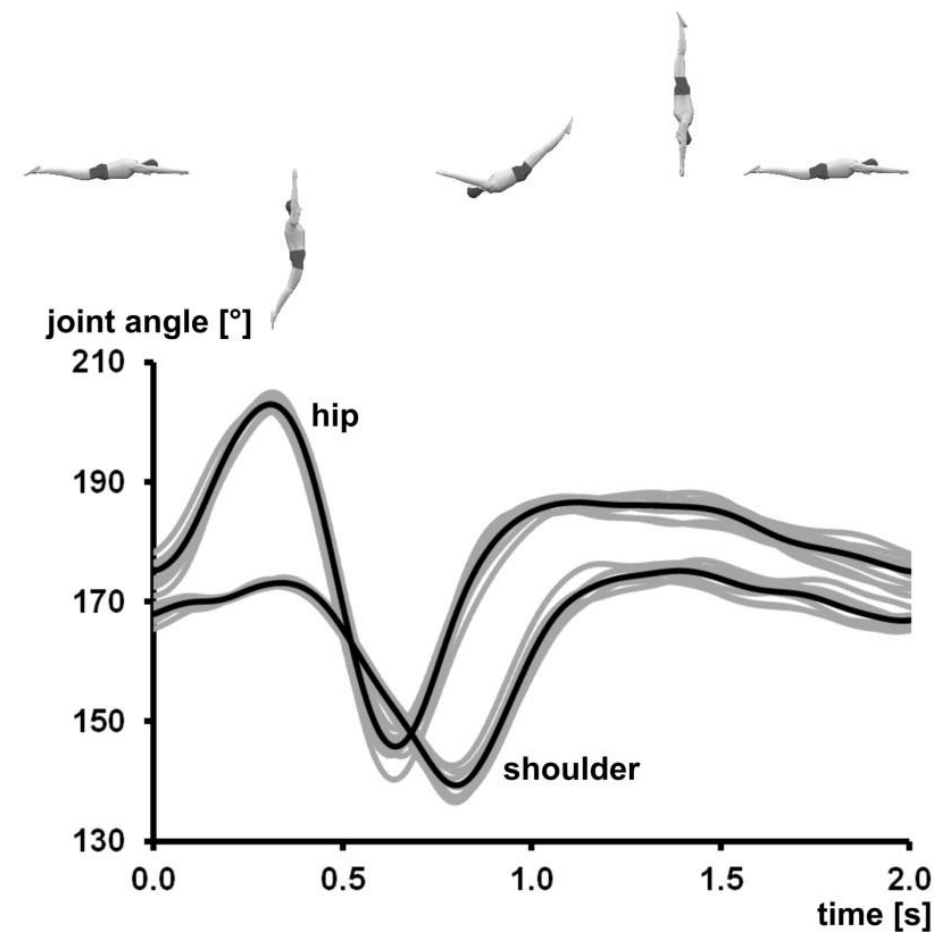

Figure 3. Typical joint angle time histories at the hip and shoulder (grey lines, $n=10$ ) and the average joint angle time histories (black lines).
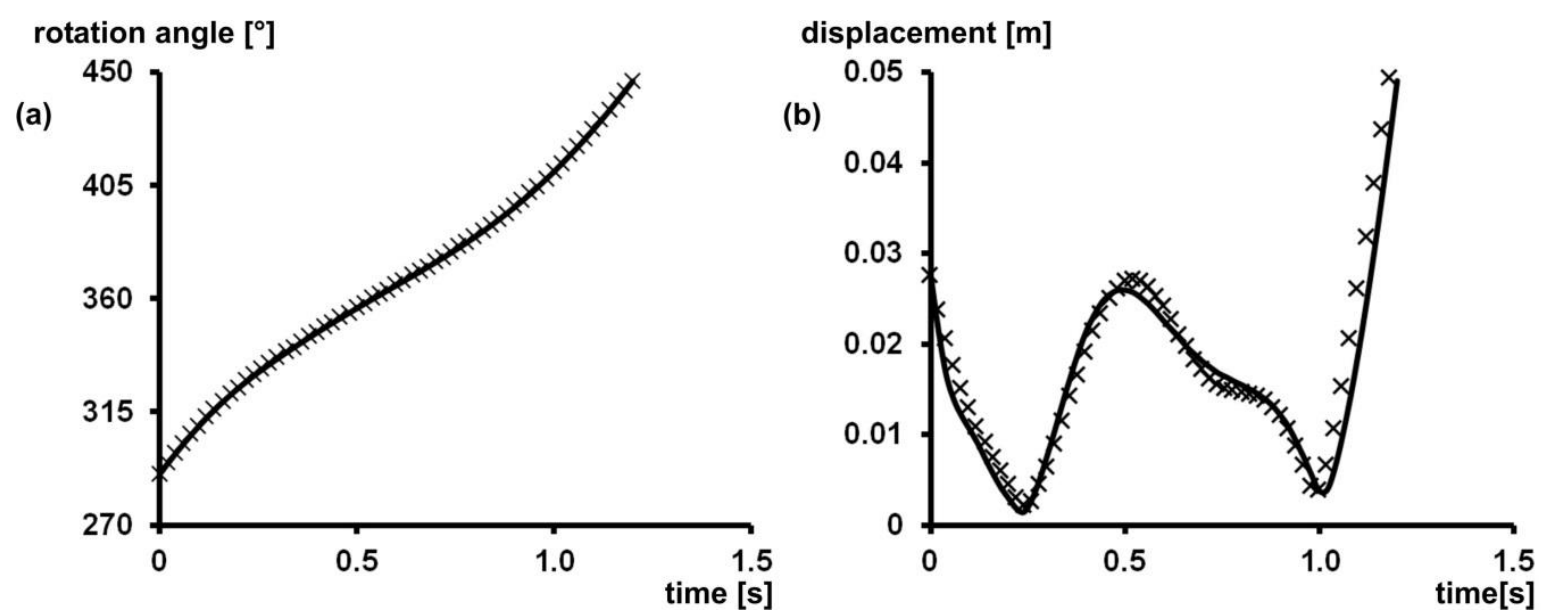

Figure 4. Typical time history of the recorded (crosses) and matching simulation (solid lines) of the (a) rotation angle and (b) bar displacements.

\section{Control Strategies}

Two control strategies were tested to determine how the gymnasts were able to reduce the variation in angular velocity through the upper part of the giant circle (Table 1). The first strategy was to maintain the average technique, despite the variation in whole body angular velocity at the end of the tap. This would be akin to a feedforward strategy, where the gymnast makes no changes to the planned timings of the extension 
and flexion through the upper part of the circle. The average technique was used to represent the planned feedforward aspect of the gymnast's technique, from which feedback adjustments would be made in the recorded performances. The average matching simulation for each gymnast was used as a starting point. Ten simulations were run for each gymnast where the initial whole body angular velocity was replaced by each of the values obtained from the ten trials. The whole body angular velocity at the end of each circle $\left(450^{\circ}\right)$ was determined.

The second strategy was based on the relative invariance seen in rotation angle at which the flexion (closing the hip and shoulder angles) occurs within the giant circle as demonstrated by Sevrez et al. (2009). The strategy assumes that through the upper part of the circle the gymnast attempts to perform the extension (opening of the hip and shoulder angles) at the same point (rotation angle) in each circle. For a given initial angular velocity, based on the 10 recorded trials for each gymnast, the timing of the extension was adjusted so that it was completed at the same rotation angle as in the matching simulation. The quintic splines defining the joint angle time histories were stretched or compressed in time using the method of Hiley \& Yeadon (2013, 2016). The strategy is in effect feedback control, making adjustments to the planned feedforward technique, based on the whole body angular velocity at the end of the tap. For each simulation the whole body angular velocity at the end of the circle $\left(450^{\circ}\right)$ was recorded.

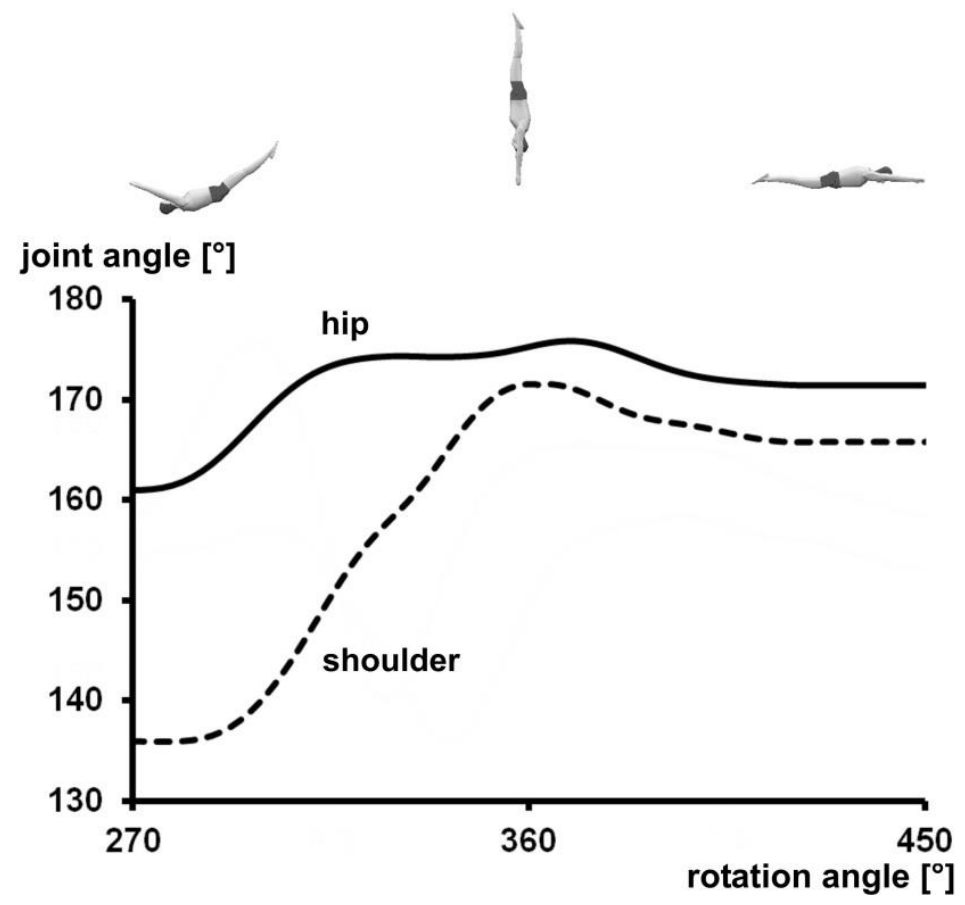

Figure 5. Hypothetical joint angle time histories at the hip (solid line) and shoulder (dashed line) used in the additional simulations.

To investigate how each strategy worked and to determine the level of passive control within the gymnast - bar system a series of simulations were performed using a hypothetical set of joint angle time histories (Figure 5). The two hypothetical joint angle time histories (hip and shoulder) were adapted from the average gymnast data. The knee was maintained at full extension throughout the simulations since this was a close approximation to all recorded trials. The hypothetical hip and shoulder time histories allowed the following sets of simulations to be run: (1) average technique (fixed timing, feedforward strategy), (2) time-stretched average technique (feedback adjustments to feedforward strategy), (3) fixed configuration technique where the angles at the hip and 
shoulder were maintained throughout the simulation of the upper part of the circle (passive contribution), and (4) fixed configuration technique with the elasticity of the bar and gymnast removed. In both fixed configuration series ( 3 and 4 ) the angles from the start of the hypothetical time histories were maintained. To simplify the analysis, all simulations in this series were started from a rotation angle of $270^{\circ}$ so that the potential energy possessed by the model was the same at the start and end of the simulation. Similarly, the hypothetical joint angle time histories were adjusted so that simulations started with zero angular velocity at each joint to ensure that all simulations started with an equivalent amount of kinetic energy. The initial angular velocity of the model was chosen to be representative of the gymnasts' performances. For each of the above conditions nine simulations were run with the initial whole body angular velocity varied from $-12 \%$ to $12 \%$ in steps of $3 \%$. The range was selected to be representative of the three gymnasts' trials. In order that all simulations started with the same amount of energy, for the fixed configuration technique with a stiff gymnast and bar (4) the energy that would have been stored in the springs was added to the kinetic energy of the gymnast model.

\section{RESULTS}

All three gymnasts showed similar patterns of variability in the magnitude and timing of the minimum and maximum angles at the hip and shoulder to Hiley et al. (2013). Through the lower part of the circle (Figure 1, (1) and (2)) the gymnasts were very consistent (Table 2). Through the upper part of the circle (Figure 1, (3) and (4)) the gymnasts were more variable in terms of timing (Table 2).

Table 2. Variation of joint actions (average of hip and shoulder) through the lower (1) and (2) and upper (3) and (4) parts of the giant circle

\begin{tabular}{cccccccc}
\hline & \multicolumn{2}{c}{$\begin{array}{c}\text { standard deviations at (1) and (2) } \\
\text { joint angle } \\
{\left[{ }^{\circ}\right]}\end{array}$} & $\begin{array}{c}\text { standard deviations at (3) and (4) } \\
\text { tims] }]\end{array}$ & $\begin{array}{c}\text { rot. angle } \\
{\left[{ }^{\circ}\right]}\end{array}$ & $\begin{array}{c}\text { joint angle } \\
{\left[{ }^{\circ}\right]}\end{array}$ & $\begin{array}{c}\text { time } \\
{[\mathrm{ms}]}\end{array}$ & $\begin{array}{c}\text { rot. angle } \\
{\left[{ }^{\circ}\right]}\end{array}$ \\
\hline 1 & 1.4 & 8 & 2.2 & 2.9 & 75 & 10.2 \\
2 & 1.7 & 9 & 2.2 & 1.5 & 53 & 8.0 \\
3 & 1.5 & 11 & 2.8 & 1.3 & 54 & 6.2 \\
\hline
\end{tabular}

Note: the circled numbers correspond to the graphics in Figure 1

Both control strategies were able to reduce the standard deviation of the angular velocity at the end of the simulation in comparison to the start (Table 3). For all but one gymnast the stretched timing strategy was most effective at reducing the standard deviation (Table 3). The amount that the gymnasts were able to reduce the variability in angular velocity (standard deviation) at the end of the simulation lay between the two strategies for each gymnast (Table 3). On average for the three gymnasts, fixed timing reduced the angular velocity variation by $36 \%$ whereas stretched timing reduced the variation by $63 \%$. The mean reduction for the actual gymnast techniques was $61 \%$.

For the series of hypothetical simulations $(1,2,3,4)$, the fixed timing strategy was able to reduce the variability in angular velocity at the end of the simulation by $38 \%$. 
The stretched timing strategy was able to reduce the variability in angular velocity by $50 \%$ (Table 4). Maintaining the same shape throughout the upper part of the giant circle (Table 4, fixed configuration elastic) was able to reduce the variability by $24 \%$. Removing the elastic components from the model and using a fixed configuration technique resulted in the same amount of variation in angular velocity at the end of the simulation as at the start (Table 4).

Table 3. Comparison of angular velocity variation at $450^{\circ}$ for (a) gymnast performances, (b) fixed timing simulations, (c) stretched timing simulations

\begin{tabular}{ccccc}
\hline & \multicolumn{2}{c}{ recorded $[\% / s]$} & \multicolumn{2}{c}{ simulation [\%] } \\
gymnast & $\begin{array}{c}\text { recorded } \\
290^{\circ}\end{array}$ & $\begin{array}{c}\text { recorded } \\
450^{\circ}\end{array}$ & $\begin{array}{c}\text { fixed timing } \\
450^{\circ}\end{array}$ & $\begin{array}{c}\text { stretched timing } \\
450^{\circ}\end{array}$ \\
\hline 1 & $212.8 \pm 7.4$ & $209.6 \pm 2.3$ & $206.3 \pm 2.3$ & $206.9 \pm 2.5$ \\
2 & $217.2 \pm 3.1$ & $220.5 \pm 1.4$ & $216.4 \pm 3.0$ & $216.7 \pm 1.5$ \\
3 & $215.1 \pm 5.2$ & $209.6 \pm 2.2$ & $208.4 \pm 3.4$ & $210.3 \pm 1.5$ \\
\hline
\end{tabular}

Table 4. Final angular velocity variation for four configuration change techniques in the upper part of the giant circle

\begin{tabular}{lcc}
\hline \multirow{2}{*}{ simulation } & \multicolumn{2}{c}{ final angular velocity [\%] } \\
& average $(\mathrm{n}=10)$ & standard deviation \\
\hline (initial angular velocity) & $(215.0)$ & $(8.2)$ \\
(1) Fixed timing & 214.6 & 5.1 \\
(2) Stretched timing & 214.5 & 4.1 \\
(3) Fixed configuration elastic & 257.5 & 6.2 \\
(4) Fixed configuration stiff & 265.7 & 8.2 \\
\hline
\end{tabular}

\section{DISCUSSION}

When the gymnasts were asked to perform repeated regular giant circles it was noted that they were able to "control" for the variation in whole body angular velocity by the time they reached the end of the circle (Table 1). The actions performed through the lower part of the circle (Figure 1, (1) and (2)), which are used to increase the energy in the system (Yeadon \& Hiley, 2000; Sevrez et al., 2009), were performed with a high level of consistency (Table 2). However, since all human movement is subject to variability, whether it is caused by planning or execution errors (van Beers et al., 2004; Cohen and Sternad, 2009), by the end of this propulsive phase the level of variability in the whole body angular velocity had increased (Table 1). The subsequent actions used by the gymnasts through the upper part of the circle served to reduce the variability in whole body angular velocity in preparation for the start of the next circle, thereby having 
a functional role in enhancing the consistency of the skill. The aim of the study was to determine how gymnasts are able to control the angular velocity. This comprised the contributions of feedback control, feedforward control and any passive control inherent in the gymnast - high bar system.

Two control strategies were considered. In the first strategy the model maintained the timing of the actions at the hip and shoulder irrespective of the variation in whole body angular velocity. This would be the equivalent of performing the actions in an open loop manner, with invariance in the timing of the opening and closing of the hip and shoulder angles. The second strategy, the stretched timing technique, required the gymnast to sense/evaluate the whole body angular velocity and modify the timing of the hip and shoulder angle opening and closing so that they occurred at the same points, spatially (rotation angle), within the circle. Sevrez et al. (2009) had previously demonstrated that the actions performed as the gymnast passed through the lower part of the circle were invariant in terms of the rotation angle at which they were performed. Both strategies were able to reduce the variation in whole body angular velocity by the end of the circle (Table 3). On average the stretched timing technique strategy was able to reduce the variation the most (Table 3).

Gymnast 1 appeared to rely on fixed timing since the stretched timing resulted in slightly greater variability, while fixed timing gave the same variability as the actual performances (Table 3). Gymnast 2 and gymnast 3 both improved upon fixed timing variability by a factor of two or more with the stretched timing. For gymnast 2 this variability was similar to that of the actual performances, whereas the performance variability of gymnast 3 lay between the fixed and stretched variabilities (Table 3 ). The techniques used by the three gymnasts appeared to be individual, with gymnast 1 primarily employing a fixed timing (feedforward) technique and with gymnast 2 and gymnast 3 making use of stretched timing (feedback and feedforward).

It should be recognised that the stretched timing technique adds a feedback element onto the basic feedforward technique of an average performance. Thus the mean value of $63 \%$ reduction in angular velocity variation may be considered as an additional $27 \%$ reduction arising from feedback corrections above the $36 \%$ feedforward reduction.

(a)

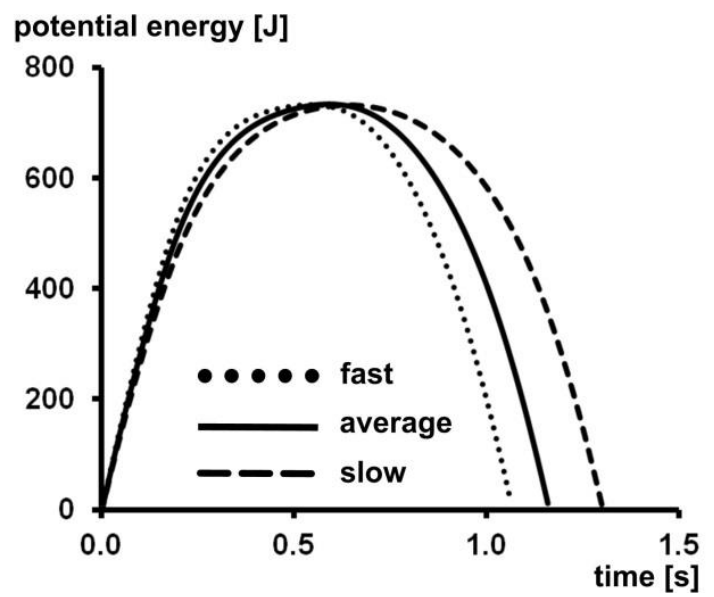

Figure 6. Relative changes in (a) potential and (b) kinetic energy for the simulations using the hypothetical joint angle time histories and the stretched timing strategy over a range of $\pm 12 \% \mathrm{~s}$ of the initial whole body angular velocity.

A set of simulations were run using a hypothetical set of joint angle time histories to establish how the stretched timing technique control strategy worked (Table 4). When considering the energy in the system, since the gymnast starts from approximately the same configuration at the end of the tap (rotation angle of approximately $290^{\circ}$ ) and ends each circle in a similar configuration, the change in energy due to gravity will be 
the same irrespective of initial angular velocity (Figure 6a). However, when the gymnast extends it is known that the potential energy will increase and the kinetic energy will decrease (Figure 6b). It can be seen in Figure $6 \mathrm{~b}$ that if the model is rotating faster the loss of kinetic energy is greater and similarly the loss is less if the model is rotating slower. Figure $6 \mathrm{~b}$ shows the relative change in kinetic energy, so while the faster giant circle may well end with more kinetic energy it has lost more energy than the slower giant circle, thus reducing the difference in whole body angular velocity at the end of the circle. This explains why both the fixed and stretched timing strategies are able to reduce the variation in angular velocity. It is interesting that the elastic properties of the gymnast - bar model also contribute to the reduction in the variability of the whole body angular velocity (Table 4). In other words, the elastic structures have a functional role in providing a degree of passive stability to the system (Wei et al., 2008). If the gymnast maintains a fixed configuration and the system is stiff (hypothetical simulations 4 ), there is no reduction in the variability of the angular velocity (Table 4).

For all three gymnasts the recorded variability in angular velocity at the end of the giant circles lay between the values obtained from the two control strategies (Table 3). This would suggest that the gymnasts were using a combination of the two control strategies. Using purely fixed timing control would lead to invariance in absolute timing, but, this does not appear to be the case from the gymnasts' movement variability data (Table 2). Using purely stretched timing control would lead to invariance in the rotation angle at which the actions through the upper part of the circle were performed. Again, this does not appear to be the case from the recorded data (Table 2). For the three gymnasts the standard deviation in the rotation angle at peak shoulder flexion (most open angle, Figure 1 (3)) were all smaller than for the peak shoulder extension (closing) and both the hip extension and flexion. The average standard deviation in the rotation angle at peak shoulder flexion (Figure 1 (3)) was less than $5^{\circ}$. Therefore, the gymnasts may have been attempting to employ the stretched timing strategy using only the shoulder angle. If they were, it might be expected that these movements would not be performed with the same precision as those performed beneath the bar (Table 2). In addition to the inherent noise within the motor system (Newell and Corcos, 1993; Cohen and Sternad, 2009) and planning errors (van Beers et al., 2004) it has been shown that humans are less able to judge movement time at slower movement speeds (Newell et al., 1979). Since the gymnast is rotating relatively slowly through the upper part of the circle (Table 1) it may be difficult for the gymnast to replicate the low timing variability seen earlier in the circle, i.e. the increased timing variability arises from a combination of slower rotation speed and feedback control.

\section{CONCLUSIONS}

Elite gymnasts control the pace of regular giant circles using a combination of feedforward and feedback techniques. On average the additional contribution provided by feedback control is the same magnitude as that provided by feedforward control. It may be concluded that both feedforward and feedback techniques make substantial contributions to the regulation of tempo/pace in performances of consecutive regular giant circles. The increased variability through the upper part of the circle plays a functional role as the gymnast makes feedback adjustments and so may be described as functional variability.

\section{ACKNOWLEDGEMENTS}

The authors wish to thank the gymnasts and coaches who gave their time to participate in the study. 


\section{CONFLICT OF INTEREST STATEMENT}

The authors wish to disclose that they have no financial or personal relationships with any people or organisations that could inappropriately influence this work.

\section{REFERENCES}

Bartlett, R., Wheat, J., \& Robins, M. (2007). Is movement variability important for sports biomechanists? Sports Biomechanics, 6, 224-243.

Bauer, W.L. (1983). Swinging as a way of increasing the mechanical energy in gymnastic manoeuvres. In H. Matsui and K. Kobayashi (Eds.), Biomechanics VIIIB. Champaign, IL: Human Kinetics. pp. 801-806.

Begon, M., Wieber, P-B., \& Yeadon, M.R. (2008). Kinematics estimation of straddled movements on high bar from a limited number of skin markers using a chain model. Journal of Biomechanics, 41, 581-586.

Cheetham, P.J. (1984). Horizontal bar giant swing centre of gravity motion comparisons. In Proceedings of the International Symposium of Biomechanics in Sports (Edited by Terauds, J., Bartheis, K., Mann, R. and Crakes, J.), pp. 99-108. ISBS. Colorado Springs.

Cohen, R.G., \& Sternad, D. (2009) Variability in motor learning : relocating, channeling and reducing noise. Experimental Brain Research, 193, 69-83.

Hamill, J., van Emmerik, R.E.A., Heiderscheit, B.C., \& Li, L. (1999). A dynamical systems approach to lower extremity running injuries. Clinical Biomechanics, 14, 297-308.

Hiley, M.J., \& Yeadon, M.R. (2003a). Optimum technique for generating angular momentum in accelerated backward giant circles prior to a dismount. Journal of Applied Biomechanics, 19, 119-130.

Hiley, M.J., \& Yeadon, M.R. (2003b). The margin for error when releasing the high bar for dismounts. Journal of Biomechanics, 36, 313-319.

Hiley, M.J., \& Yeadon, M.R. (2013). Investigating optimal technique in a noisy environment: application to the upstart on uneven bars. Human Movement Science, 32, 181-19.

Hiley, M.J. \& Yeadon, M.R. (2016). Investigating optimal technique in the presence of motor system noise: application to the double layout somersault dismount on high bar, Journal of Sport Sciences, 34, 440-449.

Hiley, M.J., Zuevsky, V.V., \& Yeadon, M.R. (2013). Is skilled technique characterised by high or low variability? - An analysis of high bar giant circles. Human Movement Science, 31, 171-180.

Jagacinski, R.J. \& Flach, J.M. (2003). Control theory for humans: Quantitative approaches to modeling performance. Mahwah, NJ: Erlbaum.

Latash, M.L. (1998). Neurophysiological basis of movement. Human Kinetics, Champaign, IL, pp. 98-105.

Newell, K.M. \& Corcos, D.M. (1993). Issues in variability and motor control. In K.M. Newell and D.M. Corcos (eds) Variability and Motor Control. Human Kinetics. Champaign, IL.

Newell, K.M., Hoshizaki, L.E.F., Carlton, M.J., \& Halbert, J.A. (1979). Movement time and velocity as determinants of movement timing accuracy. Journal of Motor Behavior, 11, 49-58.

Preatoni, E., Hamill, J., Harrison, A.J., Hayes, K., Van Emmerik, R.E.A., Wilson, C., \& Rodano, R. (2013). Movement variability and skills monitoring in sports. Sports Biomechanics, 12, 69-92,

Sevrez V., Berton, E., Rao, G., \& Bootsma, R.J. (2009). Regulation of pendulum length as a control mechanism. Human Movement Science, 28, 250-262. 
Shapiro, D.C. (1977). A preliminary attempt to determine the duration of a motor program. In D.M. Landers \& R.W. Christina (Eds.), Psychology of motor behaviour and sport - 1976 (pp. 17-24). Champagne, IL: Human Kinetics.

van Beers, R.J., Haggard, P., \& Wolpert, D.M. (2004). The role of execution noise in movement variability. Journal of Neurophysiology, 91, 1050-1063.

Wei,K., Dijkstra, T.M.H., \& Sternad, D. (2008). Stability and variability: indicators for passive stability and active control in a rhythmic task. Journal of Neurophysiology, 99, 3027-3041.

Wood, G.A., \& Jennings, L.S. (1979). On the use of spline functions for data smoothing. Journal of Biomechanics, 12, 477-479.

Yeadon, M.R., \& Hiley, M.J. (2000). The mechanics of the backward giant circle on the high bar. Human Movement Science, 19, 153-173.

Yeadon, M.R., \& Hiley, M.J. (2014). The control of twisting somersaults. Journal of Biomechanics, 47, 1340-1347.

Yeadon, M.R., \& Mikulcik, E.C. (1996). The control of non-twisting somersaults using configuration changes. Journal of Biomechanics, 29, 1341-1348.

Yeadon, M.R., \& Trewartha, G. (2003). Control strategy for a hand balance. Motor Control, 7, 411-430.

Yeadon, M.R. (1990). The simulation of aerial movement - II. A mathematical inertia model of the human body. Journal of Biomechanics, 23, 67-74. 